\title{
Impact of COVID-19 Pandemic on Physical Activity and Mental Health of Physiotherapy Students, Vadodara - A Cross Sectional Study
}

\author{
Lalli Singh $^{1}$, Devangi Desai ${ }^{2}$ \\ ${ }^{1}$ Assistant Professor, Amar Jyoti Institute of Physiotherapy, Delhi -110092, India \\ ${ }^{2}$ Sr. Lecturer, Pioneer Physiotherapy College, Vadodara -390019, Gujarat, India
}

Corresponding Author: Lalli Singh

\begin{abstract}
Background:- Lockdown in India happened due to COVID-19 pandemic. In this lockdown, government urged people to stay at home to prevent the spread of the virus. Prolonged homestay for longer duration leads to sedentary behavior which affects physical as well as mental health of the individuals.

Aim:- This study aimed at determining the impact of COVID-19 pandemic on the physical activity and mental health of physiotherapy college students. Also to know the correlation between physical activity and mental health in physiotherapy students keeping pandemic COVID-19 in between them.

Method:- A web-based survey was undertaken. 250 physiotherapy students were approached out of which 214 had successfully filled up the entire form. The questionnaire of IPAQ(SF) for physical activity level and DASS-21 for mental health were used.

Data Analysis:- Prevalence for physical activity and prevalence of mental health status for physiotherapy students was calculated and presented in form of frequency distribution and spearman's correlation was used to find the any relation between them.

Results:- Prevalence of $79 \%$ was obtained for mild physical activity. $17 \%$ for moderate physical activity and $4 \%$ severe physical activity was obtained. Prevalence of mental health status were noted it showed $29.90 \%$ mild, $32.71 \%$ moderate and $10.73 \%$ severe level of affection in physiotherapy students. Also, there is a weak positive co relation between physical activity and mental health of physiotherapy students considering pandemic.

Conclusion:- With the present study it can be concluded that there is a significant reduction in the physical activity and also prevalence for mental health status shows deterioration level among physiotherapy students. Looking at the current scenario early intervention are needed to improve the mental health status and physical activity of physiotherapy students.
\end{abstract}

Keywords: Covid 19, lockdown, stress, physical activity and health status

\section{INTRODUCTION}

The Pandemic of Covid-19 has caused various health crises all over the world. ${ }^{1}$ India is considered among the most affected country list among world. Covid-19 contains virus of single stranded RNA-Virus infecting individuals with wide range of symptoms which includes fever, cough, headache, muscle weakness, shortness of breath and diahorrea. ${ }^{2}$
In India social isolation and frequent hand wash was the first line measure taken to help and flatten the covid-19 situation, looking at the worsening situation government announced complete lockdown all over the India. ${ }^{3}$ This led to complete shutdown of all activities irrespective of colleges, schools, temples, malls, theatre, and offices. 2,3 Only the necessary commodities were allowed which included 
milk, medicines, fruits and vegetables. As there was no option left people had to stay at home. Being at home disturbs the physical activity of the individuals also the students of all colleges were allowed to go home during this lockdown. Some of them were happy to reconnect with the family again, wherein some of them have returned ${ }_{4}$ home without any hope or interest at home.

Mutating nature of virus has caused major trouble in developing the vaccines. Usually, the symptoms appear between 1 to 14 days, there are some asymptomatic behavior individuals also. ${ }^{5}$ As the situation of covid 19 got worse in other countries, government of India also took this condition seriously with making rules such a wearing mask compulsorily, sanitizing hand and social distance. Lockdown in India caused limited outdoor activities. This further led to continuously sedentary behavior. 4,5 . Sedentary behavior includes no outdoor activities, continuously watching web series, eating and playing indoor games. ${ }^{6}$

Literature suggests that for being good in mental health, physical activity is must and physical activity of the people was greatly reduced due to decrease activity of their daily routine. "As, exercises make you feel good "is an assumption and often reported to give good mental health as well as physical health.

It is evident and clinically proved that long term physical inactivity can lead to various types of health-related issues. Weight gain is the common problem which further gives rise to cardiac related problem, diabetes and many more. An individual with good physical activity has much more advantage on immunity part as well. ${ }^{7,8}$

Physiotherapy students are one of the propagators of physical activity and they are present among youths of our country. ${ }^{6}$ Physiotherapy students are made to learn about the importance of physical activity as a part of their curriculum. In lockdown as it is seen that the physical activity is greatly reduced due to lockdown. So, the level of impaction on their physical activity and any repercussions on the mental health can be studied. Also, there is a paucity of literature to find out the presence of pandemic between physical activity and mental health. So, the present study is carried out with an aim to investigate the extent to which the physical activity is reduced, also to know the jolt on the mental health of physiotherapy students and the secondary aim is to investigate the correlation between physical activity and mental health considering pandemic as one of the factors.

\section{METHODS}

A web-based survey was undertaken. International Physical activity questionnaire-short form (IPAQ-SF) was used to determine the physical activity of physiotherapy student and DASS 21 was used to check their mental health during lockdown due to pandemic Covid-19. This questionnaire was circulated to the physiotherapy students of Vadodara via Gmail in the month of august and September 2020. Both the questionnaire is validated and reliable for assessing physical activity and mental health. Ethical clearance was obtained from the institute and consent for the participation at the beginning of the study was also taken. The Survey was administered using the online survey portal, Google forms ${ }^{\circledR}$ (Online survey services). Demographic data related to age and gender was filled up by the participants. Students who were pursuing Physiotherapy course (Undergraduates), both genders and the age group between 18-25 years were included in the study. Interns and post graduate students were excluded from the study. The questionnaire was sent to 250 physiotherapy students among them the forms which were half filled/incomplete or repeated were excluded from the study. In between twice reminder was given to students in order to fill the forms. So, at the end total of 214 forms were selected for the study. Results were obtained and analyzed using Microsoft Excel and SPSS. 


\section{DATA ANALYSIS:-}

\section{Statistical tests:}

Prevalence of the physical activity and mental health during Covid-19 was presented in terms of frequency distribution and also Spearman correlation test was used to determine the relation between mental health and physical activity of physiotherapy students during covid-19 pandemic.

\section{Statistical software:}

The statistical software SPSS version 18 was used for the analysis of data and Microsoft excel and Microsoft word was used to generate graphs and tables.

\section{RESULTS}

A total of 214 out of 250 physiotherapy students, who met the inclusion criteria, were included in the study and they responded to the survey of impact of covid- 19 on physical activity and mental health of physiotherapy students.

Prevalence of physical activity and mental health in physiotherapy students during pandemic covid-19 was analyzed. In
Physiotherapy students it showed $79 \%$ had mild level of decrease $17 \%$ had moderate level of decrease and $4 \%$ had severe level of decrease in their physical activity level, similarly in prevalence of mental health status also showed level of deterioration for anxiety, stress and depression. Data analysis was done using SPSS version 18.0. Spearman's correlation was used to find the pandemic link between physical activity and mental health during Covid 19. Data were found to be statistically significant $(\mathrm{p} \leq 0.05)$, when the relation was analyzed. It shows weak positive correlation.

Demographic data is presented in table 1.

Table 1: Demographic data

\begin{tabular}{|l|l|}
\hline \multicolumn{2}{|c|}{ Table 1: Demographic data } \\
\hline Number of physiotherapy students & Values \\
\hline Age & 214 \\
\hline$(18-25)$ & Mean and Std dev \\
\hline Gender & $20+2.25$ \\
\hline & Male $=27$ \\
\hline & Female $=187$ \\
\hline
\end{tabular}

Table 2: Prevalence of physcical activity

\begin{tabular}{|l|l|c|c|}
\hline $\begin{array}{l}\text { IPAQ(SF) } \\
(\mathbf{n}=\mathbf{2 1 4})\end{array}$ & MILD & MODERATE & SEVERE \\
\hline & $79 \%(\mathrm{n}=168)$ & $17 \%(\mathrm{n}=38)$ & $4 \%(\mathrm{n}=9)$ \\
\hline
\end{tabular}

Table 3: Prevalnce of mental health

\begin{tabular}{|l|l|l|l|l|l|}
\hline TaSS 21 & NORMAL & MILD & MODERATE & SEVERE & VERY SEVERE \\
\hline Overall & $26.63 \%(\mathrm{n}=57)$ & $29.90 \%(\mathrm{n}=64)$ & $32.71 \%(\mathrm{n}=70)$ & $10.73 \%(\mathrm{n}=23)$ & $0 \%(\mathrm{n}=0)$ \\
\hline Anxiety & $23.83 \%(\mathrm{n}=51)$ & $27.57 \%(\mathrm{n}=59)$ & $36.91 \%(\mathrm{n}=79)$ & $11.68 \%(\mathrm{n}=25)$ & $0 \%(\mathrm{n}=0)$ \\
\hline Depression & $32.71 \%(\mathrm{n}=70)$ & $30.37 \%(\mathrm{n}=65)$ & $27.10 \%(\mathrm{n}=58)$ & $9.81 \%(\mathrm{n}=21)$ & $0 \%(\mathrm{n}=0)$ \\
\hline Stress & $22.89 \%(\mathrm{n}=49)$ & $31.30 \%(\mathrm{n}=67)$ & $34.58 \%(\mathrm{n}=74)$ & $11.21 \%(\mathrm{n}=24)$ & $0 \%(\mathrm{n}=0)$ \\
\hline
\end{tabular}

Table 4: Correlation between physical activity and mental health

\begin{tabular}{|c|c|c|c|}
\hline \multirow[t]{2}{*}{ Variable } & \multicolumn{3}{|c|}{ Mental health } \\
\hline & $\begin{array}{l}\text { Correlation } \\
\text { Coefficient } \\
\text { (r value) }\end{array}$ & $\begin{array}{l}p \\
\text { value }\end{array}$ & Correlation \\
\hline $\begin{array}{l}\text { Physical } \\
\text { activity }\end{array}$ & 0.308 & 0.000 & $\begin{array}{l}\text { Weak } \\
\text { positive }\end{array}$ \\
\hline
\end{tabular}

As the $r$ value obtained is $r=0.308$, it shows weak positive co relation between the physical activity and mental health but the data obtained is statistical significant with the $p \leq 0.05$.

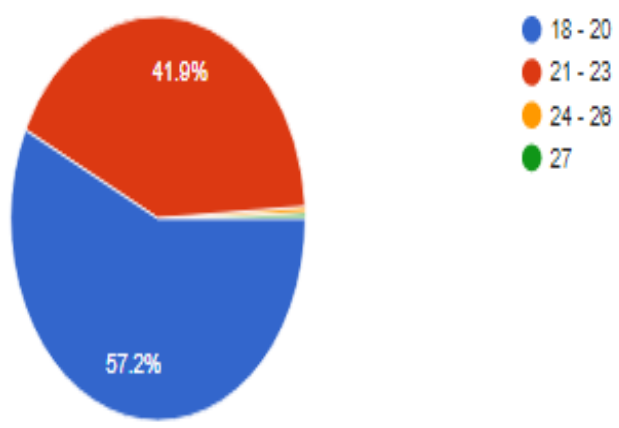

Graphical representation of age group (graph 1) Above graph shows the age distribution among the physiotherapy students. 


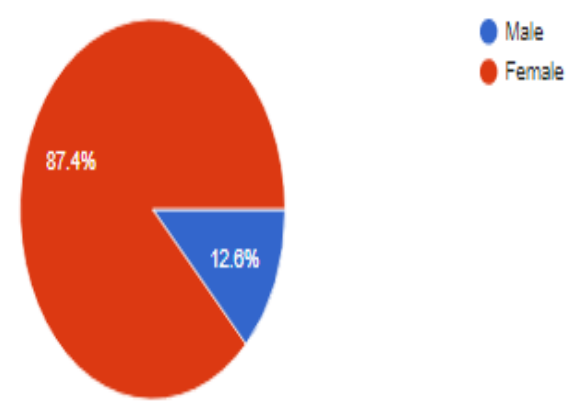

Graphical representation of Gender (graph 2) Above graph shows the distribution of male and female physiotherapy students

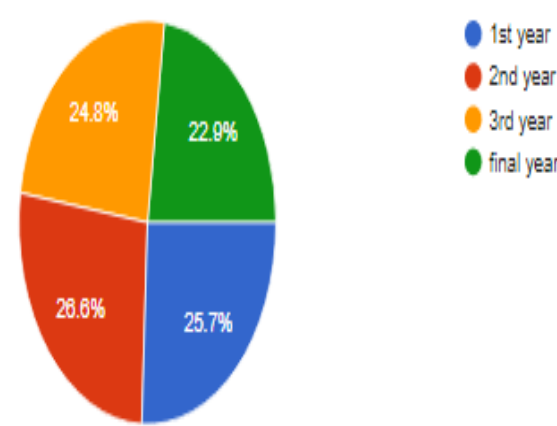

Graphical representation of distribution of students year wise (graph 3)

Above graph shows the distributions of students according to their studying years.

\section{DISCUSSION}

This study was designed to measure the impact of Covid 19 on physical activity and mental health status of physiotherapy students in Vadodara.

In the present study we found out that there is correlation between prevalence of physical activity and mental health status of physiotherapy students during Covid era too. Further it showed weak positive correlation because of small sample size

The overall result suggests that there is statistically significant $(\mathrm{p} \leq 0.05)$ correlation between physical activity and mental health of physiotherapy student. Considering the pandemic as a link the correlations shows weak positive correlation. ( $\mathrm{r}=0.38)$.

This research was done on physiotherapy students only, to report their physical activity and mental health, The web based survey was conducted as now a days students are very much active on internet platform, the Google forms were prepared and were sent to them via emails as it was the easier way to implement and less time consuming to gather the information about their daily physical activity level and mental health.

This study revealed that the physical activity and mental health were impacted due to this pandemic covid 19 in physiotherapy students. Physiotherapists have been identified as key role players in health promotion, prevention and treatment of various diseases. However, engaging in Physical activity and exercise itself is beneficial for students to obtain knowledge and facilitate learning while developing awareness into the future challenges that they will face when implementing strategic health promotion in practice. ${ }^{9,10}$

The prevalence of physical activity was decreased to a great extent. The mental health was also seen deteriorated among the physiotherapy students. When the correlation was found between physical activity and mental health among physiotherapy students data showed statistical significant with weak positive correlation with $\mathrm{r}=0.30$ and $\mathrm{p}<0.05$.

Wang et al ${ }^{11}$ conducted a study with China General population $(n=1210)$ Online survey Depression, Anxiety and Stress Scale (DASS-21); Impact of Event Scale-Revised (IES-R) where he concluded that $16.5 \%$ moderate to severe depressive symptoms; $28.8 \%$ moderate to severe anxiety symptoms; $8.1 \%$ moderate to severe stress.

A previous study was conducted to estimate physical activity levels in collegegoing students. They included students of different professions, including physiotherapy students too. They found comparable results with our study. Literatures are also available for mental health among college going students. ${ }^{12}$

Studies showed poor status of mental health of college going students before lockdown too, they were suffering 
from depression and anxiety also the Level of alcohol consumption among them was concerned, and some to look slim and fit were indulged in eating disorder and self harm. ${ }^{13}$

Narayan et al conducted a study their results indicated high degree of depression, anxiety and stress among degree college students. This burden was before lockdown, it was found that $16.4 \%, 21.1 \%, 28.1 \%$, $18.0 \%$ were having clinical depression with mild, moderate, severe and extremely severe grades and $16.4 \%$ were found to be in normal range. With respect to anxiety symptoms, $5.5 \%, 32.8 \%, 17.2 \%, 36.7 \%$ were graded as mild, moderate, severe and extremely severe anxiety and mere $7.8 \%$ fell under normal range. With respect to stress, $21.9 \%, 25 \%, 21.9 \%, 2.3 \%$ fell in mild, moderate, severe and extremely severe stress whereas $28.9 \%$ were found to be in normal range. ${ }^{13}$

To improve the conditions of young population there should be more efforts in encouraging the awareness of physical activity and mental health during this lockdown (pandemic Covid 19) with all proper and required precautions.

As seen in our results participants for physical activity were categorized into mild, moderate and severe level of physical activity wherein the maximum numbers of physiotherapy students were found to be mild level of physical activity due to this lockdown, this directly/indirectly had affected mental health of the physiotherapy students. The lectures from the home and sedentary lifestyle had leaded them to develop inactive routine and boring lifestyle. Sedentary lifestyle can cause alteration in health in adulthood.8 Regular moderate amount of exercise can lead to good response of immune system ${ }^{15,16}$

As the physical activity has more advantages on the overall health of individual, it should always be incorporated by increasing the activity level. One of the major advantage is it causes reduction in release of stress hormones ${ }^{16}$ and further it causes activation of the $t$ cell proliferation which helps in improving the health status. 16,17 This can be further supported by various the studies done on the physical activity and mental health during Covid era.

Physical activity with regular participation helps in improving the immunity of an individual thus reducing the chance of infection. Davis et al concluded in one of his study that stress in physiotherapy students is on the higher end; this stress is imputed due to the academic load and emotional problems among others. 18. Physiotherapy students can be enlightened with the development of plan and implementing change in their surroundings, most importantly environmental factors and tuning in various programs which can help in improving the physical activity.

\section{CONCLUSION}

To have healthy and balanced life, the extent of physical activity required for daily living with knowing the value of regular exercise should be incorporated and practiced. Understanding about the benefits of exercises should be encouraged across all populations. The body has a tendency to accommodate to the new change of being inactive leading to various health hazards. Henceforth preventive and proper physical activity must be taken to an advantage for benefit of all vulnerable health care workers.

\section{Limitation of the study}

- Sample size is too small to be generalized.

- Unequal distribution of students from each year.

\section{Future research}

- It can be done on larger population and in elderly population as well.

- Mental health interventions which are time-limited, can be taught to physiotherapy students and volunteers

\section{Acknowledgement: None}

Conflict of Interest: None 


\section{Source of Funding: None}

Ethical Approval: Approved

\section{REFERENCES}

1. Chen P, Mao L, Nassis GP, Harmer P, Ainsworth $\mathrm{BE}, \mathrm{Li} \mathrm{F}$. Coronavirus disease (COVID-19): The need to maintain regular physical activity while taking precautions. J Sport Health Sci 2020;9:103_4.

2. Shereen MA, Khan S, Kazmi A, Bashir N, Siddique R. COVID-19 infection: Origin, transmission, andcharacteristics of human coronaviruses. J Adv Res. 2020; 24: 91-98.

3. Atre JJ, Dandekar SP, Ganvir SS. Adherence to physical activity during COVID-19 lockdown in India- a survey. Int J Health Sci Res. 2020; 10(8):

4. Dhama K, Sharun K, Tiwari R, Dadar M, Malik YS, Singh KP, Chaicumpa W. COVID-19, an emerging coronavirus infection: advances and prospects in designing and developing vaccines, immunotherapeutics, and therapeutics. Human Vaccines \& Immunotherapeutics. 2020 Mar 19:17 58-63

5. Nieman DC, Wentz LM. The compelling link between physical activity and the body's defense system. Journal of sport and health science. 2019 May 1;8(3):201-17

6. Adarsh Kumar Srivastav, Neha Sharma and Asir John Samuel, Clinical Epidemiology and Global Health, https://doi.org/10.1016/j.cegh.2020.07.0 03

7. Lai J, Ma S, Wang Y, et al. Factors associated with mental health outcomes among health care workers exposed to coronavirus disease 2019. JAMA Netw open.2020;3(3):e203976

8. Booth FW, Roberts CK, Laye MJ. Lack of exercise is a major cause of chronic diseases. Comprehensive Physiology. 2011 Jan;2(2):1143-211.
9. DeTurk W.E. \& Scott L.B., 2008, 'Physical therapists as providers of care: Exercise prescriptions and resultant outcomes in cardiac and pulmonary rehabilitation programs in New York State', Cardiopulmonary Physical Therapy Journal 19(2), 35

10. Diana Kgokong and Romy Parker Physical activity in physiotherapy students: Levels of physical activity and perceived benefits and barriers to exercise S Afr J Physiother. 2020; 76(1): 1399.

11. Wang, C., Pan, R., Wan, X., Tan, Y., $\mathrm{Xu}$, L., Ho, C.S., Ho, R.C., 2020. Immediate psychological responses and associated factors during the initial stage of the 2019 coronavirus disease (COVID-19) epidemic among the general population in China. Int. J. Environ. Res. Public Health 17 (5), E1729.

12. Sudha B, Samuel AJ, Narkeesh K. Feasibility online survey to estimate physical activity level among the students studying professional courses: a cross-sectional online survey. J Exerc Rehabil. 2018;14(1):58-63. https://doi.org/10.12965/jer.1835130.56 5.

13. Narayan R Mutalik, Shankar Moni, S B Choudhari , Govind S Bhogale, Depression, Anxiety, Stress among College Students in Bagalkot: A College Based Study The International Journal of Indian Psychology Volume 3, Issue 4, No. 68

14. Yaghoob Nami et al. / Procedia - Social and Behavioral Sciences 114 ( 2014 ) $840-844$

15. Timmons BW, Cieslak T. Human natural killer cell subsets and acute exercise: a brief review. Exerc Immunol Rev. 2008;14(905):8-23.

16. Moraska A, Fleshner M. Voluntary physical activity prevents stress-induced behavioral depression and anti-KLH antibody suppression. Am J Physiol Regul Integr CompPhysiol. 2001;281(2 50-2):484-489. 
Lalli Singh et.al. Impact of COVID-19 pandemic on physical activity and mental health of physiotherapy students, Vadodara - a cross sectional study.

https://doi.org/10.1152/ajpregu.2001.28 1.2. $\mathrm{r} 484$.

17. Elphick GF, Wieseler-Frank J, Greenwood BN, Campisi J, Fleshner M. B-1 cell $(\mathrm{CD} 5+/ \mathrm{CD} 11 \mathrm{~b}+)$ numbers and nIgM levels are elevated in physically active vs. sedentary rats. J Appl Physiol. 2003;95(1):199-206.

https://doi.org/10.1152/japplphysiol.010 54.2002 .

18. Davis R., Campbell R., Hildon Z., Hobbs L. \& Michie S., 2015, 'Theories of behaviour and behaviour change across the social and behavioural sciences: A scoping review', Health Psychology Review 9(3), 323-344. 10.1080/17437199.2014.941722

How to cite this article: Singh L, Desai D. Impact of COVID-19 pandemic on physical activity and mental health of physiotherapy students, Vadodara - a cross sectional study. Int $J$ Health Sci Res. 2021; 11(6): 294-300. DOI: https://doi.org/10.52403/ijhsr.20210643 